\title{
O uso das novas tecnologias na educação infantil no município de Alagoa Grande-PB
}

Giovanna Barroca de Moura*

lone dos Santos Souza **

Resumo

Com a presença marcante das diferentes formas de mídias, atualmente, o mundo vive a era midiática, elevando a uma quantidade significativa de estudiosos de diversas áreas do conhecimento (educação, filosofia, psicologia, sociologia, psiquiatria) que vêm realizando pesquisas para compreender a ação das mídias no processo educativos das crianças. De acordo com essas elucidações, o professor já não pode abster da ação das mídias no cotidiano das crianças, pois, hodiernamente, é cada vez mais comum as crianças já irem para a escola com algumas noções de letramento influenciadas pelas imagens das mídias. Deste modo, o principal objetivo deste estudo foi pesquisar e analisar a formação dos professores da educação infantil do Município de Alagoa Grande-PB para o uso das tecnologias midiáticas. Realizouse uma pesquisa de campo, fundamentando-se através de um questionário apresentado aos educadores de uma instituição pública de educação infantil. Os resultados dessa investigação evidenciaram a deficiência de um planejamento voltado para o uso das TIC's em sala de aula, a falta de preparo técnico-teórico e estrutural são alguns dos problemas encontrados, diante do cotidiano de alunos e professores no processo de ensino aprendizagem.

Palavras-chave: Tecnologia da Educação e informação; Formação dos professores, Educação Infantil

\footnotetext{
* Atualmente é professora de pedagogia da Universidade Estadual Vale do Acaraú (UVA), professora substituta da Universidade Estadual da Paraíba (UEPB). Email: giovannabm@hotmail.com

* Graduanda em Pedagogia pela Universidade Federal da Paraíba. Email ione32@hotmail.com
} 


\section{The use of new technologies in child education in the city of Alagoa Grande-PB}

\section{El uso de las nuevas tecnologías en la educación infantil en el municipio de Alagoa Grande-PB}

\section{Abstract}

With the remarkable presence of different forms of media, currently, the world is living the media era, which has increased, a great deal, the amount of scholars from different areas (educations, philosophy, psychology, sociology, psychiatry), which have been conducting researches related to the comprehension of the media outcome on children's learning process. Therefore, teachers cannot ignore the power of media on children's daily routines, because, nowadays, it is becoming more common to see kids going to school already with some literacy knowledge that was acquired through the influence of images from the media. Thus, the main objective of this study was to research and analyze the formation of children's educators from the Alagoa Grande - PB municipal district, as for the use of media technology. A field research was conducted and a questionnaire was applied to the educators of a public school. The results reveal that there is a deficiency related to class planning as for the use of Communications and Information Technologies in the classroom, as well as a lack of theoretical-technical and structural knowledge. These are some of the problems found facing the daily routines of students and teachers in the learning process.

Keywords: Communications and Information Technologies, formation of children's educators, children's education

\section{Resumen}

Con la fuerte presencia de diferentes medios de comunicación, en la actualidad, el mundo vive en la era mediática, con aumento a una cantidad significativa de estudiosos de diferentes campos del conocimiento (educación, filosofía, psicología, sociología, psiquiatría) que han realizado investigaciones para entender la acción de los medios de comunicación en el proceso educativo de los niños. De acuerdo con estas aclaraciones, el maestro ya no puede abstenerse de la acción de los medios de comunicación en la vida cotidiana de los niños, pues, en nuestros tiempos, cada vez es más común que los niños ya van a la escuela con algunas nociones de alfabetización influenciados por las imágenes de los medios de comunicación. Por lo tanto, el principal objetivo de este estudio fue investigar y analizar la formación de maestros de educación infantil en el municipio de Alagoa Grande-PB para el uso de las tecnologías de los medios de comunicación. Hemos llevado a cabo un estudio de campo, basándose a través de un cuestionario distribuido a los educadores de una institución pública de educación infantil. Los resultados de esta investigación mostraron la carencia de un plan centrado en el uso de las TIC en clase. La falta de preparación técnica, teórica y estructural son algunos de los problemas que se plantean en la vida cotidiana de los estudiantes y profesores en el proceso de enseñanza y aprendizaje.

Palabras clave:Tecnología de la educación y información; Formación de profesores, Educación Infantil 


\section{Introdução}

Nas últimas décadas, diversas áreas do conhecimento educação, psicologia, filosofia, sociologia, psiquiatria e entre outras, vem se dedicando a pesquisar as relações das mídias no processo educativo das crianças. Estes estudiosos justificam seus interesses devido ao fato que a mídia está cada vez mais presente no cotidiano infantil e influenciando sua aprendizagem. Frequentemente estas pesquisas são voltadas para os alunos do ensino fundamental e médio alertando para a necessidade de serem leitores críticos da mídia, contudo, poucos dedicam suas pesquisas a pensar essa educação na educação infantil.

$\mathrm{Na}$ atualidade a mídia faz parte de todos os momentos da nossa vida o que não poderia ser diferente na escola. Desde muito pequenas as crianças em grande maioria já utilizam as novas fontes tecnológicas, seja para se comunicar dentro do contexto familiar e social ou até mesmo como fonte de diversão. Dessa forma, abrir-se um novo método de ensino-aprendizagem dando a oportunidade de trazer para dentro das nossas salas de aulas a mídia como fonte de conhecimento.

O professor da atualidade deve estar aberto a novas descobertas e a novos métodos de ensino-aprendizagem, aprimorando os recursos pedagógicos, ou seja, o professor utilizando a mídia como uma ferramenta para o desenvolvimento da sua aula. É importante que o educador crie mecanismos que possam levar as novas fontes tecnológicas para dentro da sala de aula, proporcionando um processo ensino- aprendizagem, mais dinâmico e eficaz. Porém, sabemos que não é fácil desenvolver um trabalho com as novas fontes tecnológicas pelo fato de sair de uma sala de aula, quadro de giz para uma sala de aula informatizada. Tal fato pode levar o professor a uma perplexidade, despertando insegurança frente aos desafios que representa a incorporação dos novos meios tecnológicos ao cotidiano escolar.

Além de saber como fazer uso dos meios tecnológicos no dia a dia na escola, nas aulas ministradas em sala para que as crianças consigam entender conteúdos trabalhados e construir novos conhecimentos a cerca das novas tecnologias o professor enfrenta ainda outro grande pro- blema nas escolas públicas carentes de recursos didáticos e de fontes tecnológicas.

Tudo isso nos faz percebermos que "Talvez sejamos ainda os mesmos educadores, mas certamente, nossos alunos já não são os mesmos, estão em outra" (BABIN,1989). Dessa forma o professor terá o desafio de incorporar a mídia em sua aula, levando a mídia para dentro da sala de aula.

A análise e discussão sobre o desenvolvimento deste trabalho com relação à mídia na escola pública do município de Alagoa Grande-PB ocorreu a partir da necessidade em que as pessoas têm em se comunicar no mundo e com o mundo. Para tanto, torna-se importante os meios de comunicação em massa pelo fato de proporcionar as pessoas informações sobre qualquer parte do mundo.

Objetiva-se, através deste estudo, pesquisar e analisar a formação dos professores da educação infantil do município de Alagoa Grande para o uso das tecnologias midiáticas. Procuramos evidenciar a importância da formação dos professores no uso das mídiasinserida no contexto da educação infantil como mais uma ferramenta para ser usada pelo professor em busca de melhor interação dos seus alunos com as novas fontes tecnológicas, proporcionando-lhes melhor desempenho em suas atividades e na sua interação com o mundo e com o meio social ao qual faça parte.

Com o uso da mídia como instrumento para o ensino e a aprendizagem as escolas tornarão esse processo mais dinâmico e facilitador para a mediação do conhecimento, levará a criança ao centro dos acontecimentos do mundo, midiatizando a novos conhecimentos que os fará cidadãos mais participativos, promovendo o exercício de sua cidadania para com o seu grupo social.

Tendo em vista o crescimento em ritmo acelerado das novas tecnologias e como principio de atribuir maior dinamicidade ao processo pedagógico estabelecendo maior coerência com os desafios da modernidade, concretiza-se a importância deste estudo para a prática do professor em sala de aula, principalmente pelo atual momento em que as mídias estão dominando quase todo o mundo. 


\section{O uso das TIC's na Educação}

A mídia apresenta-se como os canais ou ferramentas usadas para o armazenamento e transmissão de informações ou dados relevantes a qualquer parte do mundo em um espaço de tempo mínimo. A mídia passa a ser utilizada como sinônimo dos meios de comunicação de massa ou agências de notícias, podendo ser também referencia a um único meio utilizado para que se leve comunicação e informação de dados para qualquer lugar e finalidade.

No contexto educacional a mídia passa a ser reconhecida como uma área interdisciplinar do conhecimento, tendo como preocupação o desenvolvimento de métodos de ensino/aprendizagem que tratem da inserção dos meios de comunicação na sociedade. As ações pedagógicas deveram ser desenvolvidas de modo que venham a envolver a compreensão crítica e a participação ativa do corpo docente e discente.

Isso se deve à crescente necessidade de todos os que fazem parte desse quadro, dessa realidade educacional que neste momento se insere na realidade da educação e em praticamente todos os meios vivenciais de nossa sociedade. Gerando, a exclusão daqueles que não acompanham esse desenvolvimento. Apenas esta observação já se faz suficiente como justificativa dessa necessidade.

De acordo com Soares-Leite e Nascimento-Ribeiro (2012), o importante não é apenas utilizar as novas tecnologias em sala de aula, mas usá-las com um objetivo determinado, ultrapassando a ideia de que é apenas aprender a lidar com alguns dos recursos que este trabalho estará encerrado.

$\mathrm{Na}$ verdade, entregar estruturas e sala a professores não treinados para seu uso não representará mudança alguma. Isso porque o mediador do conhecimento na educação infantil não é aquele que transmite uma série de símbolos e códigos, fazendo com que seus alunos memorizem e aprendam a utilizar mecanicamente esses símbolos. Isso é um criador de alfabetizados funcionais.
Vendo por esse prisma podemos afirmar que a o professor da educação infantil não pode apenas fingir que não sabe ou que não percebe essa realidade. Sua ação, fundamentada na ideia de um conhecimento prévio que o mesmo possua deve lhe prover de subsídios para que possa integrar em suas práticas pedagógicas ações e atividades que o auxiliem a construir conhecimento a partir dessas novas realidades. Fazendo sua ação pedagógica passar de:

\section{(...) um sistema fragmentado de ensino para uma abordagem integradora de conteúdo e voltada para a resolução de problemas específicos do in- teresse de cada aluno. Finalmente, deve-se criar condições para que o professor saiba recontex- tualizar o aprendizado e a experiência vividos durante a sua formação para a sua realidade de sala de aula, compatibilizando as necessidades de seus alunos e os objetivos pedagógicos que se dispõe a atingir (VALENTE, 1998, p.57).}

Esse desenvolvimento interacionista auxiliará no desenvolvimento do pensamento, como processo cognitivo e marcará o modo de interação da criança com o meio que o rodeia isso se coaduna com o dito por Santos (1977, p. 33, apud SILVA, 2012, p. 112):

\begin{abstract}
O ser humano age sobre o meio, donde recolhe os dados iniciais que lhe permitirão conhece-lo. A partir dos dados iniciais percorre um conjunto de operações, que se constroem gradualmente, obtém uma representação desse mundo, pode ativar sobre ele, modificando-o, a reiniciar o caminho ante cada mudança.
\end{abstract}

Dentro dessa abordagem Orofino (2005, p. 30 ) propõe:

(...) uma educação tecnológica em que se utilize a tecnologia como um 'poderoso meio para ressignificação do mundo através da produção de conhecimento e para o investimento na autoria das crianças e dos adolescentes'.

Assim na vida pessoal e coletiva de todos os envolvidos na educação o papel da atuação se perfaz mediante a ampliação do conhecimento, porém, da aplicação de todos os meios práticos para que tal atuação seja não apenas eficiente, mas eficaz em longo prazo. 
$\mathrm{Na}$ atualidade, cada vez mais corriqueiro as crianças já virem para a escola com alguns conhecimentos referentes as imagens das mídias, em especial da televisão (Bucci, 2002). Isso se sucede por conta da mídia atingir as crianças em seu ponto mais sensível: o olhar. Para Kehl (1991), o olhar capta a imagem, antes mesmo que a palavra a nomeie. Isso provém do fato de que as crianças passam mais tempo assistindo mídia do que fazendo qualquer outra atividade não escolar. Penteado (1991) afirma que esse acontecimento já seria suscetível para trazer a mídia e seus processos no cotidiano da escola.

Segundo Martín-Barbero (2000, p.55), os meios de comunicação proporcionaram à sociedade uma multiplicidade de sabres, consequentemente a escola deixou de ser o único espaço de acesso e legitimação do saber. Este autor continua afirmar que o grande desafio da escola na contemporaneidade, manter-se atrativa e necessária aos educandos.

O desafio é também mencionado por Kaplún (1999, p. 74) quando assegura que: educar-se é envolver-se em múltiplos fluxos comunicativos. Este autor afirma que quanto mais o professor proporcionar aos alunos situações que instiguem a trama das interações comunicacionais, mais educativa será sua prática pedagógica. Diante do exposto, Soares (1999) afirma que é por meio da educação para a mídia que se pode estabelecer políticas educativas que visam minimizar os efeitos da mídia sobre as crianças e adolescentes.

Educar com e para mídias fundamenta-se numa ação diferente daquela que frequentemente encontramos em algumas escolas, nas quais, perante a ação da mídia no cotidiano das crianças, os professores se tornam obrigados a desenvolver atividades envolvendo a mídia. $\mathrm{Na}$ execução desta atividade utiliza a mídia de forma descontextualizada, ou seja, a mídia não é empregada em tarefas que permitam o aluno desenvolver a capacidade de reflexão e criticidade (NAGANINI, 1998).

O professor deve conhecer o que está acontecendo ao seu redor para que possa não apenas se informar, mas também de aprender a informar. A criança tem como referencial os adultos que estão ao seu redor, e se o professor passa a usar como referência algum personagem da mídia - como os personagens dos desenhos animados que estiverem fazendo sucesso no momento - estará reforçando a ideia de que os comportamentos de tal personagem são adequados, reforçando junto à criança esse mesmo conceito. Isso se dá porque, Le Coadic (2004, p.212) lembra que:

\section{O montante de informação na Internet leva a que se proponham questões sobre as ha- bilidades necessárias para aprender a se in- formar e aprender a informar, sobre onde ad- quirir a informação e chama a atenção de que essa aprendizagem é totalmente inexistente no sistema de ensino.}

Deste modo o processo de alfabetização não pode haver a mecanização do conhecimento, para que não haja também criação de "alfabetizados digitais", que mesmo sabendo ler e escrever, não conseguem codificar e decodificar mensagens, pois, como colocado por Buzato (2003, p. 23) destaca que:

\begin{abstract}
(...) pessoas alfabetizadas não são necessariamente "letradas". Mesmo sabendo "ler e escrever", isto é, codificar e decodificar mensagens escritas, muitas pessoas não aprenderam a construir uma argumentação, redigir um convite formal, interpretar um gráfico, encontrar um livro em um catálogo etc. A essa competência ele denomina letramento, que se constrói na prática social, e não na aprendizagem do código por si. Assim, Buzato adota o termo letramento digital por entender que não se trata apenas de ensinar a pessoa a codificar e decodificar a escrita, ou mesmo usar teclados, interfaces gráficas e programas de computador, mas inserir-se em práticas sociais nas quais a escrita, mediada por computadores e outros dispositivos eletrônicos, tem um papel significativo.
\end{abstract}

Na construção das habilidades essenciais na infância, reconhecer símbolos e fazer suas combinações adequadamente não é o objetivo principal na aprendizagem, este seria o desenvolvimento da competência em compreender, assimilar, reelaborar e chegar a um conhecimento que permita uma ação consciente. Do mesmo modo, é o que deve acontecer quando, no chamado pelo au- 
tor citado anteriormente de "letramento digital" (SILVA, JAMBEIRO, LIMA, et al, 2005, p. 34), esse letramento deve auxiliar professores a alunos no processo de "saber utilizar as TICs, saber acessar informações por meio delas, compreendê-las, utilizá-las e com isso mudar o estoque cognitivo e a consciência crítica e agir de forma positiva na vida pessoal e coletiva".

Então, colocar as pessoas em contato com as TIC's dentro ou fora da sala não é um processo automático, onde aprendendo a ligar e desligar; ou até mesmo utilizar alguns recursos não é o suficiente para formar e alimentar as necessidades cognitivas. Mas é a maneira como estes recursos devem ser vistos. $\mathrm{O}$ reconhecimento e a elaboração do pensamento a partir desses recursos, servirá de base para que se possam posicionar mediante a apresentação das ideias nelas veiculadas.

Sem essa visão, se corre o risco de formar uma geração que simplesmente aceitam o que lhes é mostrado como o ditador de ideias, onde os meios de comunicação massivamente ditam o que pode e o que não pode, o que deve e o que não deve ser consumido. Que ao aceitar a ideia imposta o que está diante dessa informação, ao consumi-la será mais alegre, mais bem-sucedida, saudável, etc. e o que não puder ter acesso, não terá felicidade.

Essa ideia errônea e consumista se forma cada vez mais cedo. Ideias são disseminadas mundialmente em questão de horas. Há momentos que estas ideias são "vendidas" de maneira tão subliminar que, mesmo para um adulto, fica difícil perceber o que é o produto do que é a ideia. Nas crianças esse efeito é ainda mais devastador, posto que sua capacidade de diferenciar o real do imaginário pode confundir-se quando na apresentação desses conceitos/ideias apresentados de maneira irresistível e insistente pelas mídias.

Porém, nem sempre é isso que acontece na prática. A evolução neste sentido atingiu limites imensuráveis, posto que em muitos momentos o público não consegue distinguir se está "cantarolando uma música da moda porque gosta de sua melodia ou porque, insistentemente, a campanha publicitária 'me convenceu a gos- tar"' (SILVA, 2012, p. 128). O mesmo se aplica aos valores culturais, que sofrem constantemente com esse direcionamento de mercado, e que nem tudo pode ser considerado como aplicável em sala de aula.

A partir dessa análise a ação pedagógica a ser utilizada deve ser pautada na formação de uma criança que possa reconhecer uma informação, interpretar e utilizar de maneira adequada as informações advindas das TIC's. A criança não pode, assim como no letramento, apenas receber a informação automaticamente e considerar como exata e inquestionável.

A educação não pode fechar os olhos para a ideia de que a criança é vista desde cedo como um consumidor, estimulado constantemente à ideia de necessidade do que está sendo exposto diante dos seus olhos e, mesmo os que são incentivados a questionar esse processo, está sendo exposto as mais diversas estratégias. Modelos que imperam na sociedade, em que estas crianças estão inseridas e que, desde cedo, essa criança já é:
(...) educada para o consumo, permite a cons- trução de valores a partir de modelos que lhe são apresentados por uma sociedade que só reconhece quem tem poder de compra e exclui quem não pode ter acesso aos bens de consu- mo (OLMOS, 2006, p.173).

Neste caso, a infância já corre o risco de sofrer as consequências a longo prazo se não forem reconstruídos conceitos baseados numa reflexão do papel da educação diante dessa revolução tecnológica que se desdobra globalmente diante de todas as sociedades. E no Brasil, as mídias e a sua relação com a educação denotam uma necessidade reflexiva acerca da função social da escola e dos profissionais da educação, no que tange à aplicação e uso das TIC's em sala de aula. Devendo essa reflexão não acontecer apenas na ação pedagógica quantitativa, mas de maneira ainda mais enfática, qualitativa, dos valores e meios empregados pelas crianças nessa nova sociedade.

As mudanças na educação, neste sentido, só poderão acontecer quando esses profissionais possam repensar o seu papel na educação, reconfigurando suas 
práticas educativas para que possam auxiliar na ampliação de competências que auxiliem no desenvolvimento do senso crítico.

\section{A importância da formação continuada do professor no uso das TIC's na educação infantil}

Com o crescimento e a ampliação do uso de meios de comunicação de maneira cada vez mais continuada o uso das TIC's na educação, seu estudo e desenvolvimento de meios para ampliá-los não é uma meta única do Brasil. Pelo que se percebe o investimento em processos pedagógicos como fornecimento de equipamentos, cursos de aprimoramento e investimento de conteúdos digitais de aprendizagem são uma das rotinas mais comuns de serem encontradas nos meios educacionais. No Nordeste, assim como em todos os Estados do país, os governos nos três níveis - municipal, estadual e federal - vêm fazendo investimentos nessas áreas, através de políticas públicas através de programas como o Programa Nacional de Informática na Educação - PROINFO, cursos de Graduação e Pós-Graduação na modalidade Educação à Distância - EAD são desenvolvidos através de plataformas desenvolvidas exatamente para esse fim (SOARES-LEITE, NASCIMENTO-RIBEIRO, 2012).

No entanto, todas essas ações não são suficientes para que esse desenvolvimento aconteça de maneira satisfatória. O Brasil é um país de dimensões continentais e, ainda não bastando, possui uma enorme diferença no que concerne às diferenças socioeconômicas em que se encontra sua população em todas as suas regiões. Isso acaba por gerar disparidades em todos os seus processos.

Há localidades onde os professores possuem laboratório de informática funcionando com sucesso e sendo adequadamente utilizado por seus alunos. Porém, em outras localidades algumas escolas contam com o mínimo possível para funcionarem com dignidade, faltando condições mínimas como: água potável, estrutura física e até mesmo energia elétrica. Isso reflete diretamente nas diferentes práticas que são desenvolvidas no seio dessas escolas. Impedindo muitas vezes aos professores e alunos a oportunidade de se tornarem participativos diante da evolução dos processos comunicativos tão característicos da modernidade em que o mundo anda mergulhado.

Nessa grande fusão de realidades se encontra a figura do professor que, de acordo com os padrões determinados pelos institutos que regem a educação no Brasil, além do investimento em infraestrutura de escolas houve pouca discussão acerca do desenvolvimento de práticas eficientes nesse sentido. Professores, coordenadores pedagógicos e diretores muitas vezes possuem grandes carências nesse sentido, ficando com dificuldades de inovação nesta área, quando os profissionais não estão seguros, sequer no uso do equipamento. $E$ às informações nessa área, acerca do desenvolvimento desse tipo de trabalho não é das mais eficientes, tendo em vista que:

\footnotetext{
A literatura não é conclusiva a esse respeito, e tal situação é atribuída, em grande parte, à ausência de indicadores específicos e consistentes e de observações sistemáticas sobre a realidade das escolas e de seus processos de ensino-aprendizagem. Para a UNESCO (2010), também é fundamental que se tenha conhecimento do impacto das TICs na aprendizagem, tanto auxiliando na formulação de políticas públicas como na tomada de decisões relacionadas ao compartilhamento do uso das TICs nas salas de aula. Para a instituição, um segundo ponto crítico existente é o uso das TICs como uma prática padrão na profissão dos educadores (SOARES-LEITE, NASCIMENTO-RIBEIRO, 2012, p. 176).
}

A capacitação adequada desses profissionais requer mais que mera vontade das autoridades. A efetiva capacitação, e não apenas teórica, no uso das TIC's, ainda não atingiu sua plenitude. Muitos profissionais que estão em sala de aula sofrem porque geralmente a teoria difere da prática, os cursos disponíveis nem sempre são suficientes para atender as necessidades.

Percebe-se que, de acordo com Brunner (2004) não há problema algum em encontrar a informação necessária, seja por parte do aluno ou do professor. O grande problema é aprender e ensinar a classificar, interpretar e usar a informação. Isso exige uma cognição mais acentuada e um olhar crítico e interpretativo das informações dispostas. 
Dessa maneira a assertiva de que a formação não acompanha o nível de desenvolvimento tecnológico. Isso porque as mudanças necessárias que são próprias para esse desenvolvimento são difíceis de serem aceitas pelos profissionais que orientam. Como pelos professores que não desejam muito sair da zona de conforto em que se encontram.

$\mathrm{O}$ acesso a certos itens faz com que se criem tecnologias que nem sempre são acompanhadas sequer pelos que formatam esses espaços e conteúdos que vão nortear esses profissionais. Enganam-se aqueles que pensam que as possibilidades de formação estão restritas a estes ou aqueles instrumentos. A velocidade desenvolvimentista na área tecnológica exige também o desenvolvimento na mesma velocidade da formação do professor, e isso muitas vezes, cria obstáculos ainda mais difíceis, posto que essas tecnologias se referem não:

(...) apenas a Internet, mas o conjunto de tecnologias microeletrônicas, informáticas e de telecomunicações que permitem a aquisição, produção, armazenamento, processamento e transmissão de dados [e informações] na forma de imagem, vídeo, texto ou áudio (MARTINEZ, 2004 p. 96).

Desse modo, afirmar que as práticas pedagógicas não acontecem na mesma velocidade com que acontecem as mudanças e avanços tecnológicos em detrimento apenas da capacitação dos docentes não é uma verdade absoluta. Pode ser um dos motivos que parcialmente causa as principais dificuldades desses profissionais, entretanto, também são faces dessas dificuldades outros problemas.

A capacidade que há de se digitalizar informações, em um sistema de comunicação tão veloz quanto é a internet hoje, um processamento e difusão cada vez mais rápidos, com custos cada vez mais reduzidos acaba tornando o acompanhamento dessas mudanças muito difícil. Porém, não há como fugir dessa realidade.

Essa sensação de velocidade segundo Valente (1997, p. 181) dão uma sensação volatilidade, isso porque:
(...) esses avanços tecnológicos têm desequilibrado e atropelado o processo de formação, fazendo com que o professor sinta-se eternamente no estado de "principiante" em relação ao uso das TICs na educação. Uma das soluções para tentar viabilizar a capacitação de professores, sem removê-los da sala de aula, têm sido os cursos à distância. Ao invés de o professor se deslocar até o local onde ele recebe a instrução, o material instrucional vai até o professor.

Os cursos mais prolongados, que são feitos à distância, mostram como as tecnologias passaram a fazer parte das vidas de todos os que participam do processo ensino-aprendizagem. Nas sociedades atuais, um ponto em comum a todas elas é a emergência da tecnologia. Ela vem através de novos processos, programas e produtos cada vez mais, o usuário comum tem acesso ao seu acompanhamento.

Desse modo, os cursos de formação de professores, mesmo os que são à distancia, devem ter sua parte presencial focada na prática. Para que possam, de domínio da teoria, se apropriarem à prática, atendendo, assim, a necessidade de adaptação e compreensão que as suas práticas pedagógicas necessitam.

Muitos professores, porém, resistem a essas adaptações - vamos assim chamar - por conta da aparente segurança que uma sala de aula formal traz. Dar aula é, neste caso, é mais importante que "perder tempo" com essas novidades, que resultam em dificuldades de controlar a turma, confusão e insegurança no que os colegas da escola irão pensar acerca de suas práticas.

Outro motivo existente, que também pode explicar essa resistência por parte dos professores, é que a apropriação e incorporação de novas práticas pedagógicas demandam um esforço adicional e, principalmente, de tempo para planejamento e elaboração de aulas. Ou seja, além do tempo necessário para o planejamento das atividades curriculares normais, as chamadas "atividades tradicionais," seria necessário ainda mais tempo para o planejamento destas novas práticas pedagógicas (SOARES-LEITE, NASCIMENTO-RIBEIRO, 2012, p. 181). 
Os autores afirmam ainda, no que encontramos plena concordância, que muitos professores em razão dos baixos salários precisam trabalhar em mais de uma instituição, acumulando trabalho extra sala e o tempo restante não é o suficiente para planejar, elaborar e avaliar novas técnicas que atendam as necessidades dos alunos em relação às TIC's, tempo esse, que a maioria dos professores não dispõe. Neste caso, a busca de novas técnicas, nada mais seria que a busca de ainda mais trabalho para si. 0 que em última instância, não procede, porque ele terá de adaptar-se de um modo ou de outro, e com um planejamento adequado essa necessidade será atendida de maneira mais eficiente e eficaz.

\section{Metodologia}

Tendo em conta a proposta deste trabalho, optou-se por utilizar o método qualitativo que, segundo Deslauriers (1991) é na pesquisa qualitativa que o cientista é ao mesmo tempo o sujeito e o objeto de suas pesquisas. $\mathrm{O}$ desenvolvimento da pesquisa é imprevisível, tendo como objetivo produzir informações aprofundadas capaz de produzir novos elementos.

Segundo Medeiros e Oliveira (2011) a pesquisa qualitativa é diferente da quantitativa por não usar a estatística como base articuladora e análise das informações.

Investigar a natureza dos fenômenos sociais é o cerne das preocupações dessa abordagem qualitativa, tendo em vista que as situações complexas tratadas por essa abordagem não podem ser simplesmente mensurada para serem compreendidas em sua essência. Essa abordagem torna-se necessária na investigação sobre fatos passados ou quando se dispõe de pouca informação, substituindo uma simples informação por dados qualitativos (MEDEIROS; OLIVEIRA, 2011, p. 636, vol.8)

Segundo a afirmação deste autor, refleti sobre a importância que deve ter os que realizam uma pesquisa qualitativa. Ela é uma pesquisa que ao aproximar o pesquisador do objeto pesquisado possibilita um contato aproximado da realidade pesquisada, mesmo sabendo que as descobertas são limitadas e que um mesmo objeto de estudo pode ser investigado em diferentes ângulos e a partir de diversas áreas do conhecimento. Por conta dessas circunstâncias, me propus dentro de limites e possibilidades aproximar o melhor possível do imaginário dos professores da Educação infantil em relação às implicações da mídia no processo de aprendizagem das crianças, mesmo reconhecendo que ainda assim, existem elementos que escapam ao olhar do pesquisador.

A pesquisa realizou-se em três instituições públicas de Educação Infantil, todas localizadas no município de Alagoa Grande situada no brejo paraibano. Participaram quatro professoras para este estudo. Uma professora entrevistada possui formação superior incompleta, outra docente apresenta nível superior e duas são especialistas.

\section{Resultados e discussões}

O primeiro item do questionário foi acerca de alguma formação sobre o uso da mídia como fonte de aprendizagem em sala de aula, durante a formação acadêmica das mesmas. Os resultados apresentados demonstram que $75 \%$ das professoras possuem em sua formação acadêmica um conhecimento formal acerca da mídia. Isso porque o estudo das TIC's já é indicado em todos os documentos que norteiam a educação em nosso país. Posto que em seus textos nos indicam que:

\footnotetext{
É indiscutível a necessidade crescente do uso de computadores pelos alunos como instrumento de aprendizagem escolar, para que possam estar atualizados em relação às novas tecnologias da informação e se instrumentalizarem para as demandas sociais presentes e futuras. (BRASIL, 1998, p. 96).
}

O mesmo documento, vêm em outro momento reafirmar que "as tecnologias da comunicação e da informação e seu estudo devem permear o currículo e suas disciplinas." (BRASIL, 1999, p. 134). É relevante ressaltar o fato que a única participante que informou não ter desenvolvido nenhum estudo nesse sentido ser a professora que possui formação acadêmica incompleta, contudo, com mais de dez anos de sala de aula. 
O segundo questionamento abordado na pesquisa foi acerca da participação de algum curso de capacitação referente ao trabalho com as Novas Tecnologias da Comunicação no processo de ensino/aprendizagem. $\mathrm{E}$ as respostas aduzidas demonstram que três destas profissionais já participaram de formação na área para que pudessem lidar de maneira mais eficiente com os recursos que hoje em dia se tornam tão comuns no cotidiano. Entretanto, a entrevistada que não possui formação acadêmica, afirma não haver participado de nenhuma capacitação por não possuir uma formação completa na área. Pode-se afirmar que diante do crescimento e da necessidade premente que se há de lidar com o crescimento tecnológico, e tendo, o professor a prioridade de mediar à aprendizagem, deve ele próprio ser o mediador de sua aprendizagem.

A pergunta na sequência, questionou junto às entrevistadas se as mesmas faziam uso de algum instrumento tecnológico no decorrer de suas aulas, e as respostas encontradas nos mostram que todas as entrevistadas afirmam que fazem uso de algum instrumento em sala de aula, e os instrumentos citados pelas participantes podem ser assim dispostos: TV, DVD, Câmera digital, Data show e retroprojetor.

Podemos observar que, mesmo a professora que não apresenta em sua formação conhecimentos acerca das TIC'S, não exclui a utilização em sala de aula, do mesmo modo, como todas as outras profissionais. Comprovando assim, a hipótese inicial desta pesquisa, que afirma a importância desses recursos para a educação em sala de aula do ensino infantil. Mesmo que não se tenha uma formação não há como ignorar a força desses instrumentos, sendo necessária uma maior atenção para com seu uso em sala de aula, para que possam transformar-se em instrumentos úteis e eficazes com seus objetivos educacionais.

O próximo questionamento foi investigar em que sentido a mídia influencia na formação das crianças como cidadãos críticos e reflexivos. As respostas foram:

PROFESSORA 01-."Quando estimulados a refletir de forma correta o que estão vendo."

PROFESSORA 02 - "Leva nossos alunos a copiarem sempre o que a mídia nos apresenta, só que na maioria das vezes, não estão os tornando críticos, mas sim, alienados."
PROFESSORA 03- "Pois tudo é no mundo da tecnologia"

PROFESSORA 04-."A professora não opinou a esse respeito"

Através das respostas acima se pode observar que as professoras entrevistadas demonstram a preocupação com um ponto em comum: os alunos estão inseridos em uma sociedade tecnológica. Através da fala da Professora 03, mesmo incompleta em relação ao questionado, ainda assim, demonstra que essa é uma realidade comum, não apenas aos alunos, mas também aos professores. Como essa realidade influencia essas crianças deve ser o objeto de reflexão também dos professores.

Para a inclusão dessas tecnologias da educação, de forma positiva é necessária à união de multifatores, dentre os quais, pode-se destacar como mais importantes: o domínio do professor sobre as tecnologias existentes e sua utilização na prática, e isso passa, necessariamente por uma boa formação acadêmica; que a escola seja dotada de uma boa estrutura física e material, que possibilite a utilização desses materiais em sala de aula; que os governos invistam em capacitação para que o professor mantenha-se atualizado e motivado (SOARES-LEITE, NASCIMENTO-RIBEIRO, 2011, p. 175).

Nas falas das Professoras 01 e 02, há a plena demonstração da necessidade de reflexão acerca do que essa realidade traz não apenas ao que se pode aprender, mas, no que podem influenciar tanto positiva, quanto negativamente na formação dessas crianças.

E finalmente, foi solicitado que as professoras citassem quais as principais dificuldades em trabalhar essas fontes de comunicação em sala de aula na educação infantil, e as respostas foram:

PROFESSORA 01 - "A falta de aparelhos tecnológicos suficientes na escola."

PROFESSORA 02 - "Não encontro dificuldades, uma vez que minha escola nos dá subsídios para tal uso."

PROFESSORA 03- "Por ter uma turma bastante numerosa isso dificulta muito o meu trabalho."

PROFESSORA 04 - "Na escola onde trabalho não tem essas fontes de comunicação a não ser TV e DVD." 
$\mathrm{Na}$ atualidade, o acesso a celulares, jogos e vários outros meios além dos citados pelas professoras no decorrer da pesquisa não é uma realidade restrita. Muitos alunos têm que conviver na mais tenra idade com esses meios, e os professores muitas vezes optam por não explorar essas fontes por motivos bem definidos que são: o tempo que será demandado para planejar essas aulas; a necessidade de pesquisa e aprofundamento no estudo da temática.

Nas falas das entrevistadas há a visão clara de todos os problemas que, durante a pesquisa referencial-teórico foram encontrados. Problemas estruturais como equipamento e acesso aos mesmos, conhecimento acerca do assunto, falta de busca de informações sobre o assunto, despreparo para ir contra a mídia institucionalizada que domina o cenário educacional a partir de uma ótica mercadológica, demonstram a necessidade extrema de se pensar sobre o assunto e buscar uma maneira de lidar com ele de maneira adequada na escola.

E isso não é um movimento novo na educação. A pauta onde as TIC's entram em grau de importância elevado já há algumas décadas. E o que se espera é que os profissionais de educação não esperem que esta revolução aconteça apenas fora da escola. Mas que contribuam para que essa mudança aconteça de maneira, senão adequada, mas, pelo menos produtiva para todos os envolvidos.

O debate sobre a revolução científica e tecnológica e suas consequentes transformações nas subjetividades, nas representações sociais e na cultura, constitui-se, hoje, como ponto de pauta na agenda da educação desse século. (...) É preciso, em vez disso, promover a convergência entre o patrimônio humanista da educação e a inventiva tecnológica, buscando um saber competente que permita à educação caminhar em paralelo com o avanço da ciência e da tecnologia (BEZERRA e COSTA, 2012, p. 146).

Neste caso, a necessidade essencial para que isso aconteça é que os professores percebam que essa mudança só será possível quando se ampliarem suas próprias percepções acerca do contexto socioeconômico, político e cultural da sociedade que o rodeia. Tendo essa consciência e essa percepção mais aguçada, poderá repensar o seu próprio papel enquanto educador do ensino infantil.

A tecnologia de maneira muito rápida vem ocupando espaços cada vez maiores na vida das pessoas e nas escolas, não são diferentes. A discussão acerca da adaptação da educação infantil é uma necessidade e não uma decorrência desse movimento social. Discussão, reflexão e prática devem andar juntas para que esse processo possa acontecer da maneira menos negligente possível, indo exatamente pelo caminho oposto: buscando analisar sua presença e sua importância para uma fase tão determinante para a criança quanto a da educação infantil. Todo esse processo deve buscar a evolução de sua atuação profissional, acadêmica e educacional.

\section{Considerações finais}

A evolução tecnológica é uma marca deste século que não se pode negar. Entretanto, a educação não consegue acompanhar esta evolução a contento. Os fatores que dificultam esse pareamento entre educação e as TIC's apesar de já haver previsão legal nas normas que regem o sistema educacional do Brasil - se funda na necessidade de formação daqueles profissionais que podem ser chamados de "ponta de lança", posto que estão em contato com aqueles para quem é pensado todo o processo educacional: a criança.

E educação infantil é um dos pontos mais importantes em todo o sistema educacional, pois eles são aquela geração que está sendo formado em plena era da comunicação globalizada. Neste caso, a importância de se refletir sobre as práticas pedagógicas adotadas são de vital importância, pois esse não é um processo que se possa retroceder. As mudanças chegaram e são de uma amplitude global. Como profissional, o professor, na busca de conhecimento e embasamento técnico-teórico terá nessa preparação seu único caminho seguro.

A complexidade da temática, se associa a falta de recursos como material didático, estrutura física, tempo disponível, experiências práticas em relação às teorias, acabam por dificultar a criação de espaços de ação específicos e dificuldades de estruturação e organização 
de práticas eficientes nos espaços de aprendizagem da educação infantil.

Podemos trazer a este momento o dito por Demo (2012, p. 9), quando este afirma que costuma "girar em torno do desafio da 'aprendizagem' do estudante e do professor", porque considera "um dos males mais intestinos do sistema atual o 'instrucionismo': pedagogias da reprodução". O que é uma das mais coerentes observações, isso porque os professores, devido a inúmeros fatores, ainda acreditam que dará menos trabaIho manter sua forma atual de trabalho do que tentar adaptar-se de maneira mais produtiva ao uso das TIC's na educação infantil.

O uso de alguns recursos como TV e DVD não é o suficiente para ser considerado como utilização das novas tecnologias. Essas práticas - o uso das TIC's - devem ser marcado pelo pensar em informação. Discutir estratégias para o uso dessas tecnologias implica em se pensar em uma educação na perspectiva da interação, da discussão, do questionamento do que se apresenta diante dos olhos.

A aceitação incondicional e a memorização das informações já não é mais sinônimo de aprendizagem. A reformulação da visão de mundo, o diálogo, a mudança, esses são os novos conceitos em aprendizagem. A mediação reflexiva deve ser a marca da prática pedagógica. Onde desde cedo à criança deve ser levada a perceber a importância da análise do que lhe é apresentado. Ela deve ser, desde cedo, exercitar o diálogo, interagindo. Refletindo acerca dos conceitos que lhe forem apresentados e a partir de suas conclusões podendo criar sua própria visão de mundo.

E ainda, tanto para professores, quanto para alunos, a reformulação da visão do mundo não pode ser um processo definitivo, mas uma constante, e que essa visão deve modificar-se à medida, em que aprenda a reinterpretar tudo à sua volta, posto que a constante mutação que a sociedade vive, é um processo contínuo, e o aprender a aprender tornou-se um lema ainda mais vigente na modernidade. Conclusivamente podemos afirmar que professores ainda precisam muito crescer e desenvolver sua visão crítica em relação às suas próprias práticas no uso das TIC's na educação infantil. E mais importante ainda, é que podemos afirmar que este é um processo que já está acontecendo e que, a amostra explorada nesta pesquisa, demonstra que se exige cada vez mais ampliação de conhecimentos e esforços conjuntos de todos que fazem o sistema educacional não apenas em Alagoa Grande, mas no Brasil inteiro.

\section{Notas}

* Giovanna Barroca de Moura Possui mestrado em Cooperación al Desarrollo pela Universidade de Valência (Espanha, 2011), especialização em Saúde Mental pela Faculdades Integradas de Patos (2009), bacharelado em Pedagogia pela Universidade Federal da Paraíba (2008), licenciatura em Psicologia pela Universidade Federal da Paraíba (2009) e formação em Psicologia pela Universidade Federal da Paraíba (2013). Atualmente é professora de pedagogia da Universidade Estadual Vale do Acaraú (UVA), professora substituta da Universidade Estadual da Paraíba (UEPB). Email: giovannabm@hotmail.com

** Ione dos Santos Souza Graduanda em Pedagogia pela Universidade Federal da Paraíba. Email ione32@hotmail.com

\section{Referências}

BABIN, Pierre. Os novos modos de compreender - a geração do audiovisual e do computador, São Paulo, Edições Paulinas, 1989.

BEZERRA, Lebiam Tamar Silva. COSTA, Isabel Marinho da. Ensinar e aprender na sociedade da informação. In: DIAS, Daniele dos Santos Ferreira. BEZERRA. Ed Porto (Org.). Mídias e formação docente. João Pessoa: Editora Universitária da UFPB, 2012.

BUZATO, Marcelo E. K. Letramento digital abre portas para o conhecimento. Entrevista ao Educarede em 23 jan. 2010. Disponível em http://www.educarede.org.br

BRASIL. Secretaria de Educação Fundamental. Parâmetros Curriculares Nacionais: introdução aos parâmetros curriculares nacionais. Brasília: MEC/SEF, 1998.

BUCCI, Eugênio. A publicidade é boa escola de política. Revista Nova Escola, p.14, maio. 2002.

DEMO, Pedro. Educação, Avaliação Qualitativa e Inovação. Brasília: Instituto Nacional de Estudos e Pesquisas Educacionais Anísio Teixeira, 2012.

DESLAURIERS, J P. Recherche qualitative; guide partique. Québec (Ca): McGraw-Hill,Éditeurs,1991

KAPLÚN, Mario. Processos educativos e canais de comunicação. Revista Comunicação \& Educação, São Paulo, vol. 14, nº 68 a75, jan./abr., 1999.

KEHL, Maria Rita. Imaginar e pensar. In: NOVAES, Adauto. Rede imaginária. São Paulo: Companhia das letras, 191. 
LE COADIC, Y.-F. Princípios científicos que direcionam a ciência e a tecnologia da informação digital. Transinformação, Campinas, v. 16, n. 3, p. 205-213, set./ dez. 2004.

MARTÍN-BARBERO, Jesús. Dos meios às mediações. Comunicação, cultura e hegemonia. 2. ed. Rio de Janeiro: Ed. UFRJ, 2000.

MARTÍNEZ, Jorge H. Guitiérrez. Novas tecnologias e o desafio da educação. In: TEDESCO, Juan Carlos (Org.). Educação e novas tecnologias: esperança ou incerteza?; tradução de Claudia Berliner, Silvana Cobucci Leite. São Paulo: Cortez;Buenos Aires: Instituto Internacional de Planeamiento de La Educacion, 2004.

MEDEIROS, José Washington de Morais; OLIVEIRA, Zenon Sabino de. Trabalho de Conclusão de curso. IN: Trilha do Aprendente. Edna de G. Brennand, Silvio José Rossi (organizadores) João Pessoa: PB, v. 8, L. 2. Editora Universitária __ UFPB__ Pedagogia a Distância, 2011, p.636.

NAGANINI, Eliana. Televisão, publicidade e escola. In: CHIAPPI$\mathrm{NI}$, Ligia. Aprender e ensinar com textos não escolares. São Paulo: Ed. Cortez, 1998.

OROFINO, M. I. GADOTTI, Moacir. Mídias e mediação escolar: pedagogia dos meios, participação e visibilidade. São Paulo: Cortez: Instituto Paulo Freire, 2005.

OLMOS, Ana. Consumismo infantil está virando um caso de saúde pública. Jornal A Gazeta, caderno Cidades, de 17/09/2006.

PENTEADO, Heloisa Dupas. Televisão e escola, conflito ou cooperação? São Paulo: Cortez, 1991

SILVA, Margarida Sonia Marinho do Monte. Mídia televisiva e infância. In: DIAS, Daniele dos Santos Ferreira., BEZERRA. Ed Porto (Org.). Mídias e formação docente. João Pessoa: Editora Universitária da UFPB, 2012.

SILVA, Helena; JAMBEIRO, Othon; LIMA, Jussara; BRANDÃO, Marco Antônio. Inclusão digital e educação para a competência informacional: uma questão de ética e cidadania. Ciência e Informação, Brasília; v. 34, n.1, p.28-36, jan./abril, 2005.

SOARES, Ismar de Oliveira. Comunicação e criatividade na escola. São Paulo: Paulinas, 1999.

SOARES-LEITE, Werlayne; NASCIMENTO-RIBEIRO, Carlos Augusto Stuart. A inclusão das TICs na educação brasileira: problemas e desafios. Magis, Revista Internacional de Investigación en Educación [On-line] 2012, 5 (Julio-Diciembre): [Data de consulta: 20/05/2014] Disponível em:<http://www.redalyc.org/articulo.oa?id=281024896010 > ISSN 2027-1174.

VALENTE, José. Armando; ALMEIDA, Maria Elizabeth Bianconcini. Visão analítica da informática na educação no Brasil: a questão da formação do professor. Revista Brasileira de Informática na Educação. V. 1, n. 1, p. 45-60, Julho 1997.
Data de Recebimento: 05 de setembro de 2014

Data de Aprovação: 18 de outubro de 2014

Data de Publicação: 30 de dezembro de 2014 
